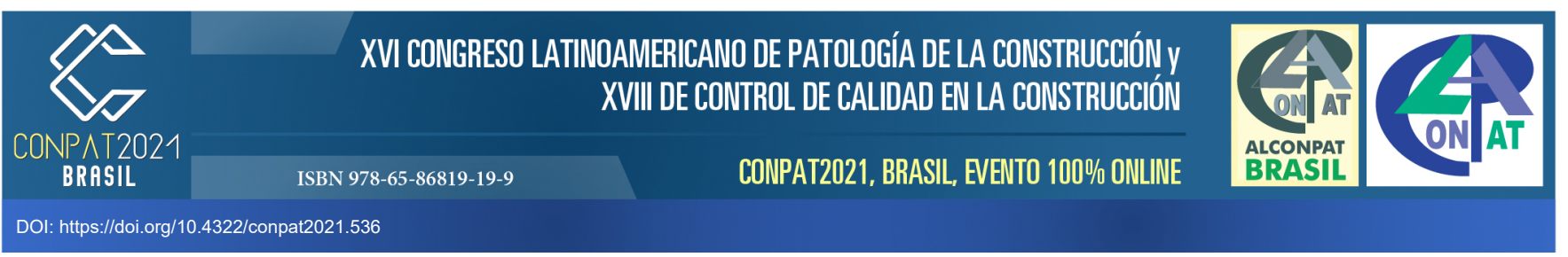

\title{
Análise de fissuras em edificações educacionais com sistema estrutural pré-moldado na cidade de Santa Rosa/RS
}

\author{
K. S. B, Chrischum (1); A. P, Maran (2)*; M. F. F, Menna Barreto (3); M. M, Copetti (4) \\ *Autor de Contacto: anapaulamaran@gmail.com
}

(1) Curso de Engenharia Civil, Universidade Regional do Noroeste do Estado do Rio Grande do Sul (UNIJUI), Santa Rosa, Brasil.

(2) Curso de Arquitetura e Urbanismo, Universidade Federal de Santa Maria (UFSM), Cachoeira do Sul, Brasil.

(3) Programa de Pós-Graduação em Engenharia Civil (PPGCI), Universidade Federal do Rio Grande do Sul (UFRGS), Porto Alegre, Brasil.

(4) Curso de Arquitetura e Urbanismo, Universidade Federal de Santa Maria (UFSM), Cachoeira do Sul, Brasil.

\section{RESUMO}

A durabilidade das edificações é um fator fundamental a ser considerado durante a etapa de concepção, visando o desempenho das estruturas. As fissuras são manifestações patológicas de larga ocorrência em edificações, podendo apresentar os primeiros sinais de degradação.. As fisssuras podem surgir de várias formas e com diversas tipologias, gerando desconforto ao usuário ou, com maior gravidade, apontar a instabilidade estrutural da edificação. Sendo assim, este trabalho busca analisar a presença deste tipo de manifestação patológica recorrente em construções por meio de um estudo de caso em um imóvel edificado com o sistema construtivo pré-moldado em Santa Rosa/RS. A ocorrência de fissuras neste sistema é ocasionada pela movimentação estrutural e características dos materiais componentes, como a interface de alvenarias e elementos estruturais.

Palavra-Chave: Durabilidade; Manifestações Patológicas; Fissuras; Estruturas Pré-moldadas. 


\begin{abstract}
The durability of buildings is a fundamental factor to be considered during the design stage, aiming at the performance of the structures. Over time, buildings can present pathological manifestations, where fissures are more frequent. Cracks can arise in various ways and with different types, which can cause discomfort to the user or, with greater severity, point to the structural instability of the building. Therefore, this work seeks to analyze this type of recurrent manifestation in buildings through a case study in a building built with the precast construction system in Santa Rosa/RS. The presence of cracks in this system occurred by the structural movement and characteristics of the component materials, such as the masonry interface and structural elements.
\end{abstract}

Keywords: Durability; Pathological Manifestations; Cracks; Precast Structures.

\title{
RESUMEN
}

La durabilidad de las edificaciones es un factor fundamental a considerar durante la etapa de diseño, apuntando al desempeño de las estructuras. Con el tiempo, los edificios pueden mostrar manifestaciones patológicas, donde las grietas son más comunes. Las fisuras pueden presentarse de diversas formas y de diferente tipo, que pueden provocar molestias al usuario o, con mayor gravedad, señalar la inestabilidad estructural del edificio. Así, este trabajo busca analizar la presencia de este tipo de manifestación recurrente en construcciones a través de un estudio de caso en un edificio construido con el sistema constructivo prefabricado en Santa Rosa / RS. La aparición de grietas en este sistema es causada por el movimiento estructural y las características de los materiales componentes, como la interfaz de mampostería y los elementos estructurales.

Palabra clave: Durabilidad; Manifestaciones Patológicas; Fisuras; Estructuras Premoldeadas.

\section{INTRODUÇÃO}

$\mathrm{Na}$ construção civil, cada tipo de material ou sistema construtivo a ser empregado tem suas características próprias, que influenciam com maior ou menor intensidade a tipologia da edificação e atributos particulares. A NBR 9062 (ABNT, 2017), que indica parâmetros para projeto e execução de estruturas de concreto pré-moldado, define o sistema como "peças executadas industrialmente, mesmo em instalações temporárias em canteiros de obras, sob condições rigorosas de controle de qualidade".

Para Pederiva (2009), a racionalização obtida com esse sistema permite que os materiais sejam mais aproveitados, sem a demanda de profundas alterações tecnológicas. Assim, as obras prémoldadas proporcionam maior rapidez de execução, controle de qualidade, projetos de modulação e relativo nível organizacional de produção.

Apesar do maior controle, este tipo de sistema também apresenta manifestações patológicas recorrentes. Assim, o diagnóstico e recuperação dessas manifestações são necessários como forma de evitar a degradação precoce da edificação. Além disso, a análise de anomalias em ambientes de caráter educacional por muitas vezes se torna difícil, pela escassez de manutenção e uso intensivo da edificação, ocasionando elevado grau de degradação (Azzalin, 2005), independentemente do sistema aplicado.

Segundo Verçoza (1991), quando se conhece os problemas ou defeitos que uma construção pode vir a apresentar e suas causas, a chance de cometê-los reduz significativamente. Sendo assim, o 
estudo dos mecanismos, sintomas, causas e origens destes problemas é fundamental na manutenção e durabilidade das edificações (Cánovas, 1988).

Como diversos trabalhos apontam as fissuras como principal manifestação patológica recorrente no sistema pré-moldado (Tomé, 2010; Araujo, 2017; Ramos et al., 2018; Carvalho, 2019), este trabalho visa o estudo focado neste tipo de dano.

Para Menegatti (2008), a prevenção de fissuras exige um controle sistemático e eficiente da qualidade dos materiais e serviços, assim como a harmonia entre projeto, execução e manutenção. A presença de fissuras pode servir de alerta sobre danos mais preocupantes na edificação (Thomaz, 1989), além de atingir os usuários de maneira psicológica, através da sensação incômoda visual que remete à um problema de segurança (Antunes, 2010). Ademais, a constatação de fissuras na edificação também facilita a degradação da estrutura e os outros sistemas, como os componentes de alvenaria e revestimento.

As manifestações patológicas comumente encontradas em sistemas pré-fabricados podem ser provenientes da falha do planejamento, projeto, produção e execução, assim como fatores climáticos, características dos materiais combinados a outros sistemas e deslocamento da estrutura, entre outros. Dentre as manifestações patológicas presentes neste tipo de sistema, as fissuras apresentam ocorrência frequente, podendo ser decorrentes pela retração, variação de temperatura, esforços de tração, compressão e torção, além de recalques de fundações e movimentações higroscópicas (Camaduro e Zatt, 2000).

Dentro desse contexto, o objetivo desse trabalho foi analisar as manifestações patológicas quanto às fissuras incidentes em um conjunto de edificações destinado a atividades educacionais, executado em sistema pré-moldado, situado no município de Santa Rosa/RS, apresentando o diagnóstico com as possíveis causas e a indicação de possíveis reparos, como forma de amenizar os danos já existentes, prevenir seu agravamento e o desenvolvimento de outras manifestações e garantir o melhor desempenho da edificação.

\section{PROCEDIMENTO}

A obra estudada é um conjunto de edificações destinado a atividades dividido em três blocos, onde as observações das manifestações patológicas ocorreram em todas as salas destinadas às atividades acadêmicas de aulas, junto aos blocos A e B do campus Santa Rosa/RS. A edificação analisada foi construída em sistema estrutural pré-moldado em esqueleto, combinado com alvenaria de vedação executada em tijolos cerâmicos furados e sistema de lajes em duplo T.

A metodologia adotada para o desenvolvimento do estudo é composta pelas etapas de levantamento das manifestações patológicas através de avaliação visual in loco, o diagnóstico das manifestações encontradas e, por fim, a definição de métodos de recuperação, conforme mostra a Figura 1. 


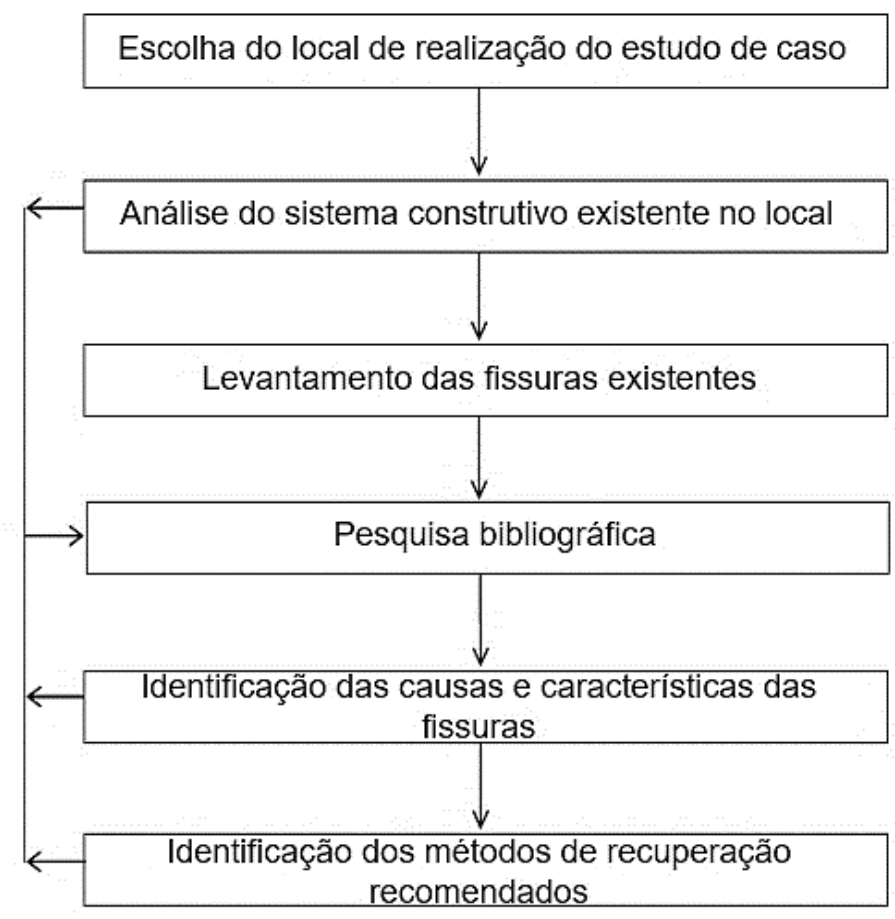

\section{RESULTADOS E DISCUSSÕES}

Com a inspeção visual e através de documentação fotográfica, realizou-se o registro das principais tipologias de fissuras encontradas, a fim de determinar, em função de suas características, as suas causas e métodos de recuperação, conforme segue.

\subsection{Fissuras à $45^{\circ} \mathrm{em}$ alvenaria}

As fissuras à $45^{\circ} \mathrm{em}$ alvenarias de vedação, presentes em edifícios com estrutura reticulada, podem ser ocasionadas em função da junção de materiais com diferentes coeficientes de dilatação térmica, sujeitos a movimentação térmica dos elementos. Outro fator que pode ser considerado para esta tipologia é a acomodação da estrutura, ocasionando a deformação excessiva (Sampaio, 2010). A incompatibilidade entre propriedades dos blocos de vedação e argamassa de assentamento também pode ser considerada como causa, visto que a fissura acompanha a interface entre esses materiais. Este tipo de fissura é mostrado na Figura 2.

Para a recuperação, inicialmente, deve-se verificar se a estrutura está estabilizada quanto às movimentações, para então realizar o processo de reparo. O método de Tomé (2010) pode ser empregado neste caso, realizando a aplicação de material selante flexível, para a possibilidade de acompanhamento do reparo em caso de movimentações, evitando maiores danos. No caso de paredes com revestimento em argamassa, pode-se ainda realizar a colocação de uma tela sobre a trinca e posterior pintura. 


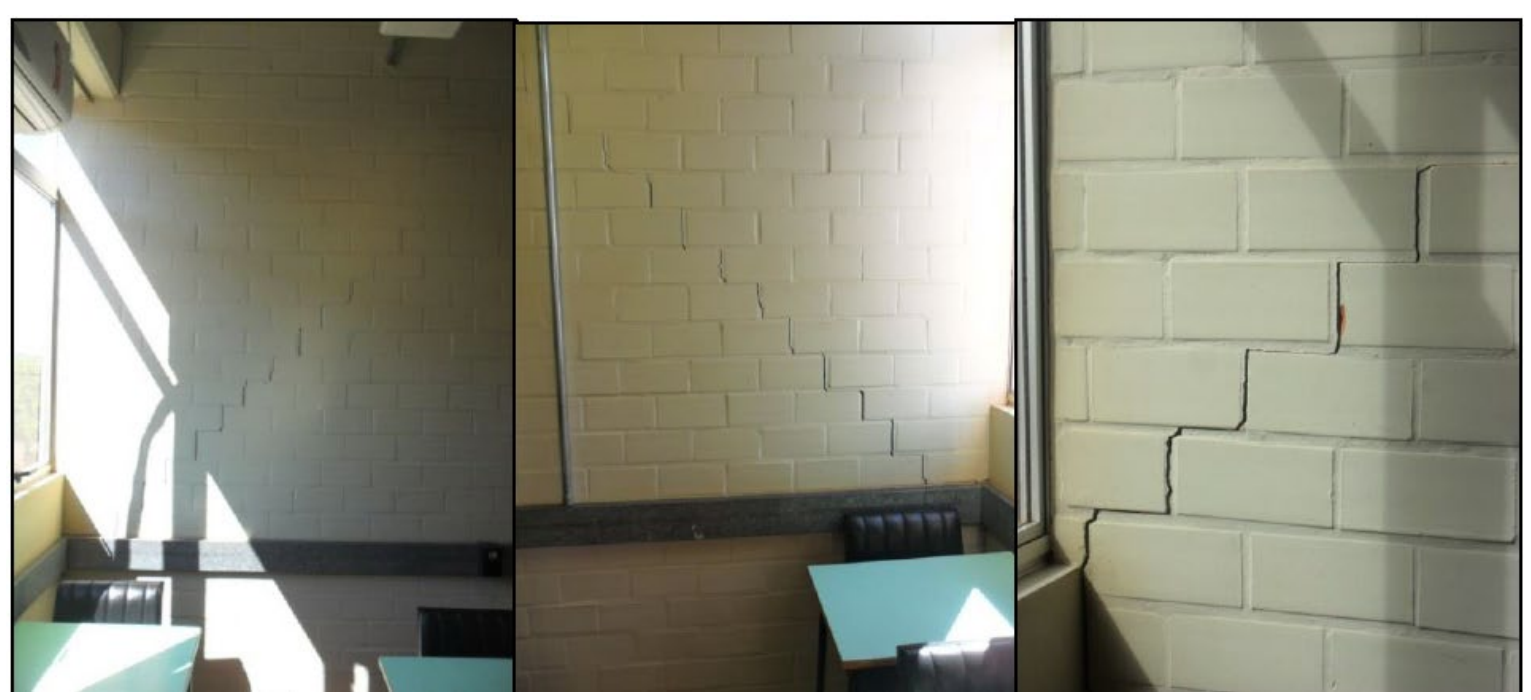

Figura 2: Fissuras a $45^{\circ} \mathrm{em}$ alvenaria (autoria própria)

\subsection{Fissuras no encontro dos elementos}

O destacamento vertical entre as alvenarias e o reticulado estrutural pode ser ocasionado por movimentação térmica diferencial, falta de itens de amarração dos planos, comportamento estrutural e deformações desiguais (Figura 3).

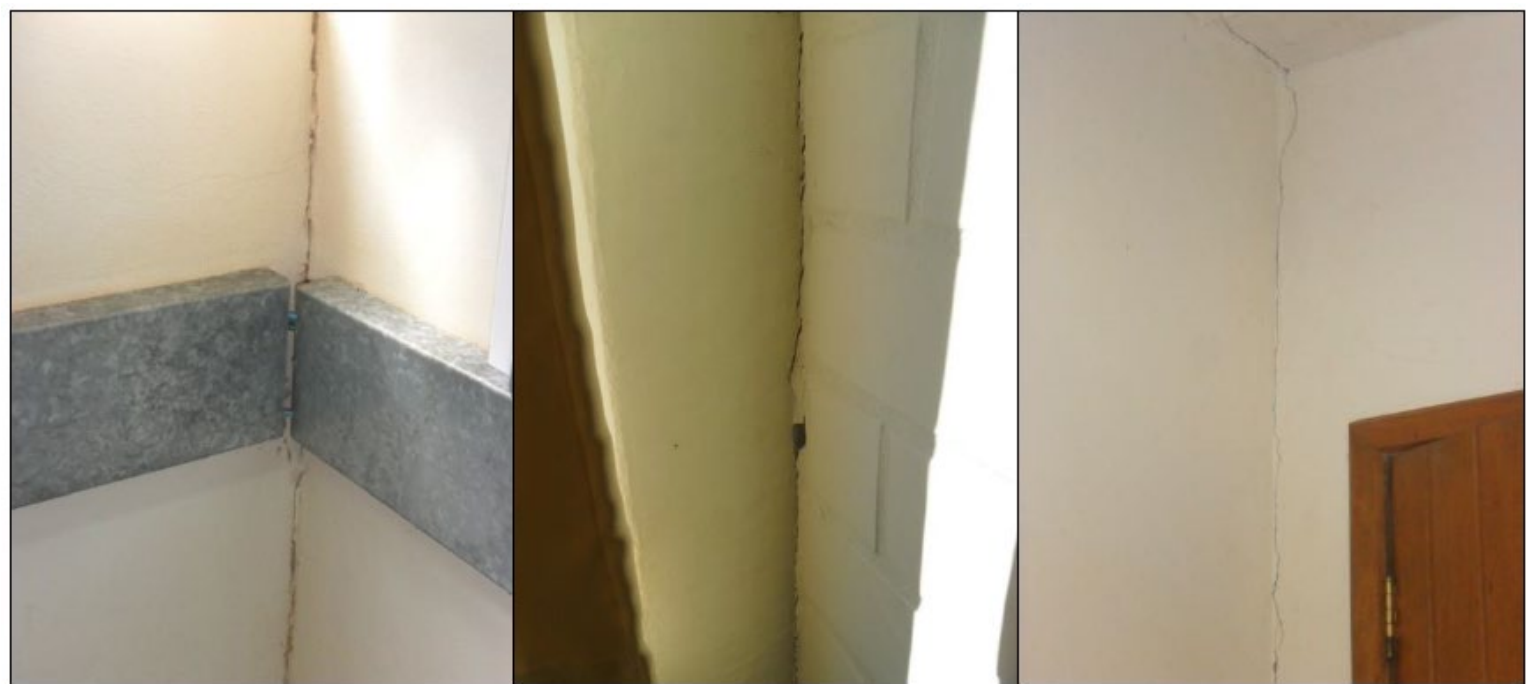

Figura 3: Fissuras de destacamento entre ligações de estrutura/vedação (autoria própria)

A parede de alvenaria e os elementos de concreto são dois conjuntos distintos, com composições e características diferentes e com isso, irão se deformar de maneira diferente de acordo com os esforços solicitantes (de força e temperatura). Deste modo, é necessário utilizar-se de um artifício que promova rigidez no encontro da parede com o pilar. Para isso, pode-se empregar o uso de telas, inseridas a cada duas fiadas no assentamento da unidade da alvenaria, e quando possível, utilizálas também na argamassa de revestimento, transpassando os elementos aproximadamente em 20 cm para cada lado, como mostra a Figura 4. 


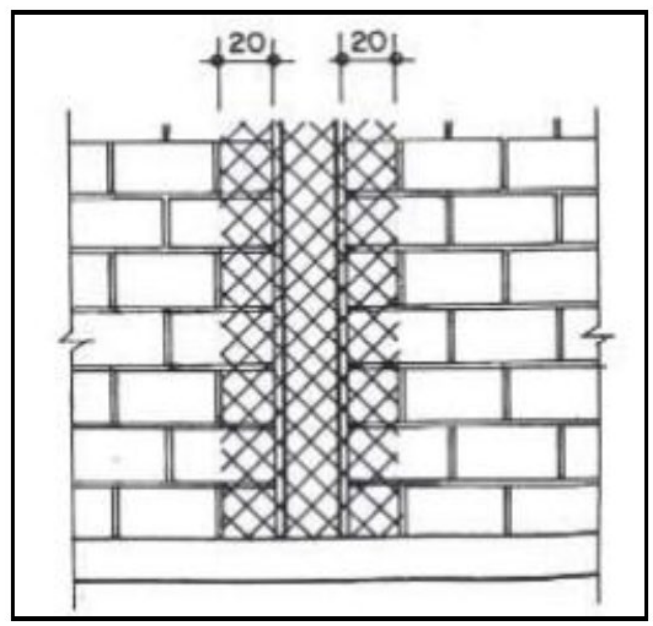

Figura 4: Técnica de recuperação entre pilar e alvenaria (THOMAS, 1989)

No caso da Figura 3, como a estrutura ainda pode sofrer movimentações, recomenda-se a utilização de materiais flexíveis para o preenchimento/tratamento das fissuras já aparentes. Esta aplicação garantirá a vedação completa das fissuras, além de permitir a movimentação entre os materiais sem aparecimento de novos danos.
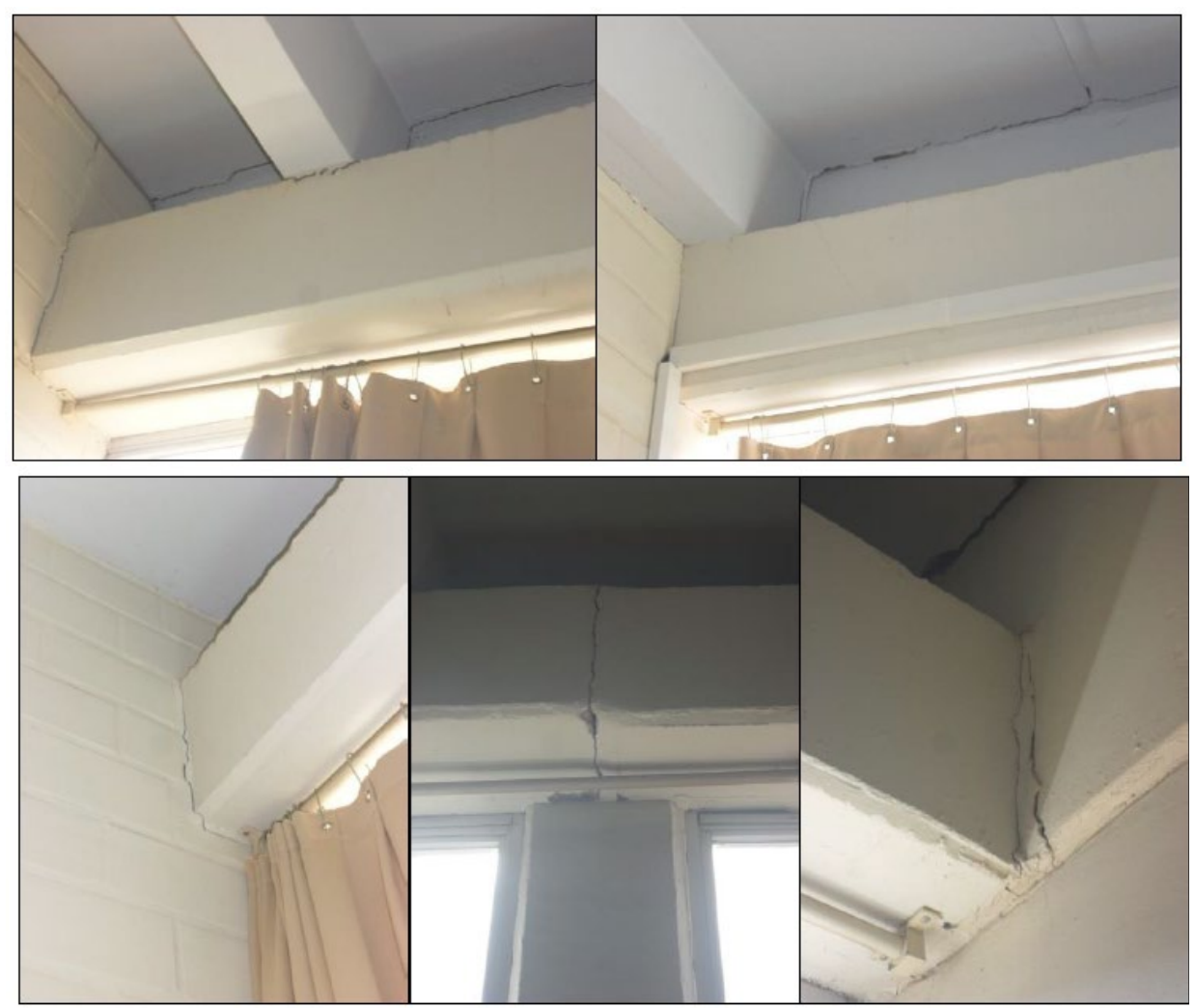

Figura 5: Fissura no encontro dos elementos (autoria própria) 
Uma das soluções previstas para esta manifestação patológica é a vedação das juntas já existentes, e para isso, pode-se utilizar produtos selantes de alto desempenho, tornando a união dos elementos mais resistentes e diminuindo a probabilidade de ocorrência dessa manifestação.

Os selantes atuam como uma barreira eficaz contra a passagem de calor, luz, som, água, vapor e poeira, devendo resistir e absorver dilatações, deformações e vibrações. Este tipo de selante apresenta comportamento elástico, ou seja, ocorre as deformações proporcionais às tensões aplicadas e retornam ao seu estado original após o término destas tensões (Oliveira, 2013).

\subsection{Fissuras horizontais em alvenarias}

As causas deste tipo de fissuração (Figura 5) podem estar associadas a movimentação higroscópica do material, a partir da presença de umidade. Pode-se associar esta causa, uma vez que as fissuras horizontais observadas se encontram próximas ao piso e em parte da edificação em contato com o solo.

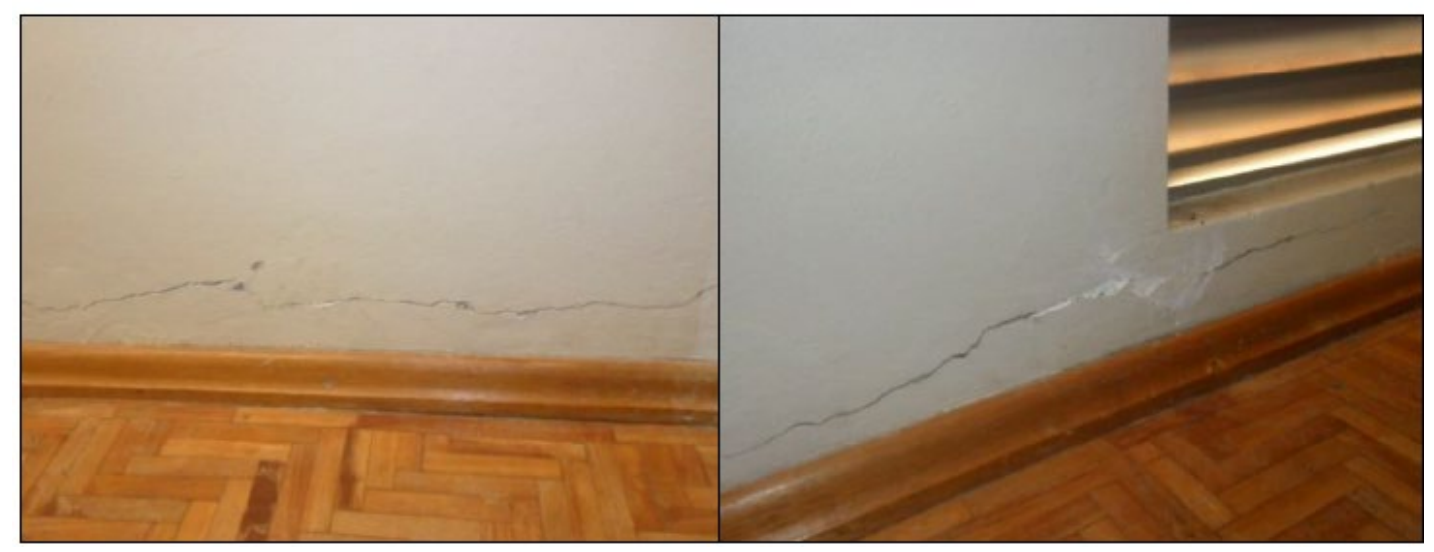

Figura 6: Fissuras horizontais (autoria própria)

As fissuras causadas por movimentações higroscópicas são semelhantes às fissuras ocasionadas por movimentação térmica. Ambas são consequência de deformações provocadas por variações volumétricas (expansão e contração). $\mathrm{O}$ aumento do teor de umidade produz uma expansão do material enquanto a diminuição provoca uma contração deste material, podendo causar esse tipo de fissuração.

Uma indicação para recuperação desta manifestação é a retirada do revestimento e impedimento da ação de umidade. Desta forma, após limpeza da base é possível utilizar impermeabilizantes cristalizantes, por exemplo (SOCOLOSKI, 2015) e após o período de aplicação revestir novamente a parede com argamassa.

\subsection{Fissuras sobre vigas}

Observou-se a incidência de manifestações patológicas originadas por esmagamento dos elementos estruturais, como mostra a Figura 7. Segundo Helene (1992), este tipo de fissura representa a possível sobrecarga em pontos localizados na estrutura. 


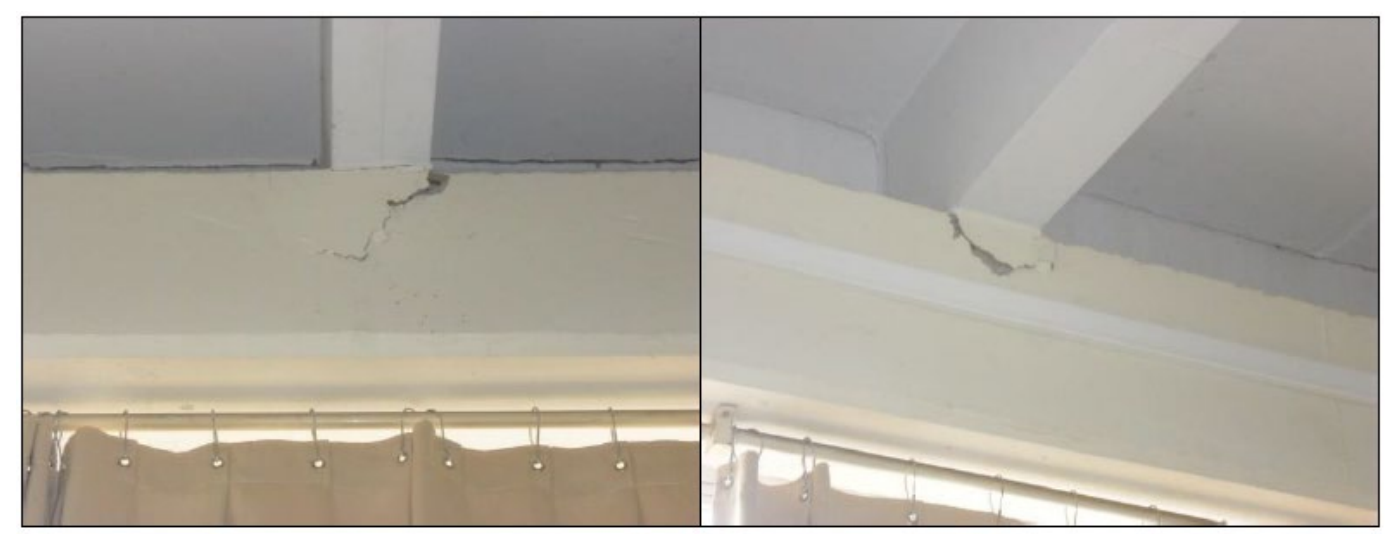

Figura 7: Fissuras sobre as vigas (autoria própria)

Para a recuperação deste tipo de fissura, deve ser realizada a retirada do revestimento e aplicação de nova argamassa e posterior pintura. Cabe salientar que esta manifestação deve ser acompanhada, a fim de verificar se o dano surgiu de forma pontual por acomodação do sistema estrutural/vedação ou se representa um possível problema estrutural ativo.

\title{
3.5 Análise de incidência de fissuras nas edificações
}

O gráfico apresentado na Figura 8 mostra a incidência de fissuras encontradas de acordo com as características apresentadas anteriormente. Pode-se verificar que o maior índice de fissuras existentes corresponde àquelas que possuem aberturas com inclinação de aproximadamente $45^{\circ} \mathrm{em}$ alvenaria devido a incompatibilidade do material de vedação e argamassa de assentamento.

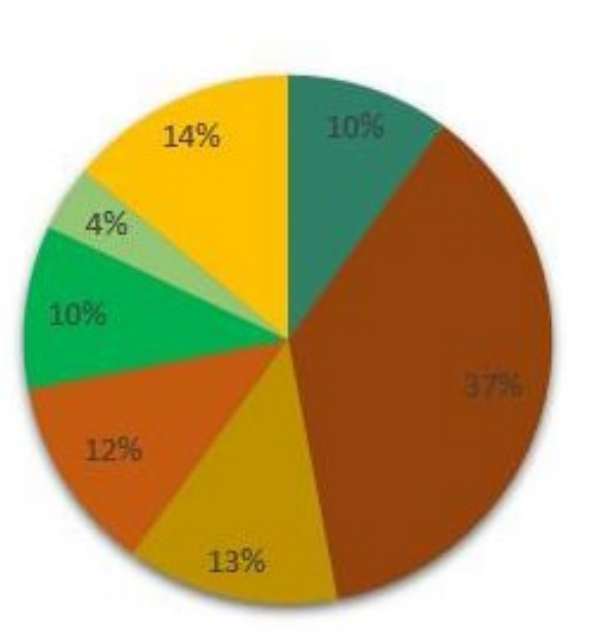

\author{
Fissuras no encontro alvenaria/laje \\ Fissuras em alvenaria $\left(45^{\circ}\right)$ \\ - Fissuras em alvenaria (horizonta is) \\ Fissuras no encontro de vigas \\ Fissuras sobre as vigas \\ Fissuras em alvenaria (vertica is)
}

Fissuras no encontro alvenaria/pilar

De um modo geral, para a indicação de recuperação das manifestações patológicas foram considerados métodos para a não reincidência das fissuras a partir do tipo de ocorrência. De forma geral, recomenda-se a limpeza do substrato onde se encontra a fissura e da abertura e a aplicação de material flexível. Como exemplo, o uso de selantes a base de poliuretano é indicado devido a propriedades como a adesão inicial e secagem rápida, além de proporcionar uma barreira contra umidade e demais fatores externos de degradação. 


\section{CONSIDERAÇÕES FINAIS}

Ao concluir esta pesquisa, pode-se perceber que a presença de fissuras na edificação pode ter origem na concepção do sistema estrutural, assim como a sua associação com os demais elementos do sistema construtivo. A natureza das fissuras encontradas não traz risco a estabilidade estrutural da edificação a curto prazo. Entretanto, a possibilidade de infiltrações e a ação de outros agentes agressivos pode resultar, a médio e longo prazo, consequências mais sérias. Com isso, a recuperação deste tipo de manifestação se faz necessária como medida preventiva.

As principais incidências das manifestações identificadas são geradas em função de diversos fatores, podendo citar os fatores climáticos e de vibrações constantes na edificação, causando a movimentação da estrutura.

As divergências encontradas relacionadas às necessidades de materiais e componentes específicos para a ligação dos sistemas entre si, proporcionam o surgimento de fissuras.

As soluções encontradas são de fácil recuperação e execução, necessitando apenas de um projeto de manutenção do imóvel, realizado por um profissional especializado, a fim de garantir a durabilidade dos materiais, seguindo as devidas recomendações de cada fabricante.

Por fim, pode-se concluir que independente do sistema estrutural a ser utilizado, a preocupação com todos os fatores que podem vir a gerar quaisquer tipos de problema na edificação, deve ser um fator de extrema relevância, tanto na execução do projeto, quanto na elaboração do plano de manutenção deste imóvel, pois independentemente do tipo de manifestação patológicas, sempre haverá prejuízos e danos, tanto para a vida útil da estrutura, quanto para os usuários.

\section{REFERÊNCIAS}

Associação Brasileira de Normas Técnicas. NBR 9062 - Projeto e execução de estruturas de concreto pré-moldado. Rio de Janeiro, 2017.

Associação Brasileira de Normas Técnicas. NBR 15575 - Desempenho de edificações habitacionais. Rio de Janeiro, 2021.

Antunes, G. R. (2010), Estudo de manifestações patológicas em revestimentos de fachada em Brasília. Dissertação de Mestrado, Universidade de Brasília, p. 178.

Araújo, M. E. S. O. (2017), “Análise das manifestações patológicas em edificações escolares préfabricadas na cidade de Campinas/SP”. Dissertação de Mestrado. Universidade Estadual de Campinas, Campinas/SP, Brasil. p. 144.

Azzalin, M. (2005), "Building pathology database and maintenance approach in a well-defined contexto: Calabrian historical centers". 10th DBMC Internacional Conference on Durability of Building Materials and Component, Lyon: France, pp 988-994.

Camaduro, I, W. JR. Zatt, P. J. R. (2000), “Um estudo sobre fissuras em concreto armado”. Encontro Tecnológico da Engenharia Civil e Arquitetura de Maringá. Maringá, Paraná. $6 f$.

Cánovas, M. F. (1988), “Patologia e terapia do concreto armado”. São Paulo, Editora Pini. 
Carvalho, R. B. (2019), "Patologias em estruturas pré-moldadas em concreto: estudo de caso nas cidades de Palhoça-SC e São José-SC”. Monografia (Graduação em Engenharia Civil). Universidade do Sul de Santa Catarina, Brasil. p.99.

Helene, P. R. L. (1992), “Manual para reparo, reforço e proteção de estruturas de concreto”. $2^{\mathrm{a}}$ ed. São Paulo.

Oliveira, D. F. (2013), Levantamento de causa de patologias na construção civil. Universidade Federal do Rio de Janeiro. Rio de Janeiro, agosto de 2013.

Menegatti, J. B. (2008). Fissuras em fachadas: análise e incidência em edificios na cidade de Chapecó-SC. Monografia (Graduação em Engenharia Civil). Unochapecó, Chapecó, Brasil.

Pederiva, P. F. (2009), Comparação de custos envolvidos na construção de pavilhões com estruturas pré-moldadas e moldadas in loco. Monografia (Graduação em Engenharia Civil) - Ijuí, RS: Universidade Regional do Noroeste do Estado do Rio Grande do Sul, p. 65.

Ramos, M. M, Nascimento, M. L. M. Pereira, V. L. (2018), "Manifestações patológicas em estrutura de concreto pré-fabricado: estudo de caso”. $6^{\text {a }}$ Conferência sobre Patologia e Reabilitação de Edifícios (PATORREB). Rio de Janeiro, Brasil. p. 9.

Sampaio, M. B. (2010), "Fissuras em edifícios residenciais em alvenaria estrutural”. Universidade de São Paulo, São Carlos.

Socoloski, R. F. (2015), "Tratamento de umidade ascensional em paredes através de barreiras químicas por gravidade”. Dissertação de Mestrado. Programa de Pós-Graduação em Engenharia Civil. Universidade Federal do Rio Grande do Sul. Porto Alegre, Brasil. p. 138.

Thomaz E. (1996), Trincas em edifícios. São Paulo, Editora Pini.

Thomaz, E. (2002), Trincas em Edifícios - Causas, Prevenção e Recuperação. São Paulo Editora Pini, p.194.

Tomé, A. (2010), Investigação das manifestações patológicas encontradas das edificações préfabricadas da Unochapecó, campus Chapecó. Chapecó, Brasil, p. 55.

Verçoza, E. J. (1991), Patologia das Edificações. Porto Alegre, Editora Sagra, 172p. 